\title{
Polymorphic markers of the glycogen debranching enzyme gene allowing linkage analysis in families with glycogen storage disease type III
}

\author{
Jianjun Shen, Hui-Ming Liu, Yong Bao, Yuan-Tsong Chen
}

\begin{abstract}
Glycogen storage disease type III (GSDIII), an autosomal recessive disease, is caused by deficient glycogen debranching enzyme (GDE) activity. We identified three polymorphic markers in the GDE gene using single strand conformation polymorphism (SSCP) analysis and DNA sequencing. They were $-10 \mathrm{G} / \mathrm{A}$ in the $5^{\prime}$ non-translated region of exon $3,2001+8 \mathrm{C} / \mathrm{T}$ in intron 16, and 3199C/T (P1067S) in exon 25. Two polymorphic markers $(-10 \mathrm{G} / \mathrm{A}$ and $2001+8 \mathrm{C} / \mathrm{T}$ ) were highly informative in both controls and GSD-III patients with heterozygosity values of 0.50 and 0.46 , respectively. The third marker $(3199 \mathrm{C} / \mathrm{T})$ had a heterozygosity value of 0.26 . Restriction analysis of the PCR amplified genomic DNA products in two GSD-III families showed for the first time the potential use of these markers for carrier detection and prenatal diagnosis in this disease.

(f Med Genet 1997;34:34-38)
\end{abstract}

Keywords: human glycogen debranching enzyme; glycogen storage disease type III; linkage analysis; poly morphism.

Glycogen debranching enzyme (GDE), together with phosphorylase, is responsible for degradation of glycogen. The GDE is a $174 \mathrm{kDa}$ monomeric protein, with both amylo1,6-glucosidase (EC 3.2.1.33) and 1,4- $\alpha$-Dglucan 4- $\alpha$-D-glycosyltransferase (EC 2.4.1.25) activities at two independent catalytic sites. ${ }^{12}$ Deficiency of GDE activity causes glycogen storage disease type III (GSD-III), an autosomal recessive disease, characterised by hepatomegaly, hypoglycaemia, short stature, and, in many patients, progressive myopathy and cardiomyopathy. Overt liver cirrhosis can occur and gross cardiac involvement may lead to death. ${ }^{3}$ The variable phenotype is explained by differences in tissue expression of the defective enzyme. Most commonly the enzyme is deficient in both liver and muscle (GSD type IIIa). However, sometimes GDE is only deficient in liver and activity in muscle is normal (type IIIb). In rare cases, selective loss of only one of the two GDE activities (glucosidase (type IIIc) or transferase (type IIId)) has been documented. ${ }^{45}$

We and others have isolated the GDE gene and determined its cDNA sequences. ${ }^{67}$ The
GDE gene mRNA consists of a 4596 base pair coding region and a 2371 base pair $3^{\prime}$ nontranslated region. The human gene is localised to chromosome $1 \mathrm{p} 21 .^{8}$ The genomic structure of the human GDE gene has been determined and consists of 35 exons spanning at least $85 \mathrm{~kb}$ of DNA (Bao et al, manuscript submitted). ${ }^{9}$

We recently reported the first pathogenic mutation in GSD-IIIa; this mutation (4529insA) appears to be rare and has only been seen in one child with an unusually severe phenotype. ${ }^{10}$ We also identified the striking association of exon 3 mutations (17delAG and Q6X) with GSD-IIIb patients. ${ }^{11}$ However, these mutations account for less than $20 \%$ of the total mutant alleles in GSD-III. Because of the large size of the GDE gene, it is impractical to sequence the entire gene for routine diagnosis. Prenatal diagnosis using a qualitative assay or enzymatic assay requires a large number of viable cultured amniotic fluid cells or chorionic villi, which need a relative long period of cell culture, thus limiting its usefulness. ${ }^{12-14}$ Furthermore, carrier detection using these methods has not been possible. In this study, we report three polymorphic markers in the GDE gene and show the potential use of these molecular markers in linkage analysis for carrier detection and prenatal diagnosis of GSD-III.

\section{Materials and methods} PATIENTS

Our study group included 28 normal unrelated subjects and 18 patients with glycogen storage disease type III and their family members, the majority of whom were white. The patients with GSD-III were identified through our diagnostic facility for study of glycogen storage disease at Duke University Medical Center. Linkage analysis was studied in two GSD-III families. Family 1 had one affected child and a newborn baby. Family 2 had two affected children and the mother was pregnant. Blood (or cord blood from the newborn) was the source of genomic DNA.

SINGLE STRAND CONFORMATION POLYMORPHISM (SSCP) ANALYSIS

The primers in table 1 were used to amplify the coding regions and intron-exon junctions of exon 3 (primers 1 and 2), exon 16 (primers 3 and 4 ), and exon 25 (primers 5 and 6 ) of the GDE gene. The DNA fragments were labelled 
Table 1 Primers used for genomic amplifications

\begin{tabular}{|c|c|c|c|}
\hline Primer & Sequence* & Orientation & $c D N A$ coordinates \\
\hline 1 & $5^{\prime}$ cgatattttaactcctttttg $3^{\prime}$ & Sense & Derived from intron \\
\hline 2 & 5'agcacgcaaatgagcaaatc $3^{\prime}$ & Antisense & Derived from intron \\
\hline 3 & $5^{\prime}$ gctatagaatagcactttgc $3^{\prime}$ & Sense & Derived from intron \\
\hline 4 & 5'aaagttgttggecatgtagg $3^{\prime}$ & Antisense & Derived from intron \\
\hline 5 & $5^{\prime}$ cctacaagtaataaattcaa $3^{\prime}$ & Sense & Derived from intron \\
\hline 6 & $5^{\prime}$ catattttaaccttgtca $3^{\prime}$ & Antisense & Derived from intron \\
\hline 7 & 5'GTGGAGTTCTTTTAATTCTT3' & Sense & -52 to -32 \\
\hline 8 & $5^{\prime}$ cttgcctactgaCCTTGTTC $3^{\prime}$ & Antisense & 76 to $82+$ intron sequence \\
\hline 9 & 5'GTGCTAGTGGAAGTACAAGA3' & Sense & 1855 to 1874 \\
\hline 10 & 5'AAATctggacaaaggtaaa3' & Antisense & $\begin{array}{l}\text { Intron sequence }+2002 \text { to } \\
2005\end{array}$ \\
\hline $\begin{array}{l}11 \\
12\end{array}$ & $\begin{array}{l}\text { 5'CCTGCCAATTCTTTCACC 3' } \\
\text { 5'GCTAGAGAAACACAACATT3' }\end{array}$ & $\begin{array}{l}\text { Sense } \\
\text { Antisense }\end{array}$ & $\begin{array}{l}2015 \text { to } 2032 \\
2064 \text { to } 2081\end{array}$ \\
\hline
\end{tabular}

${ }^{*}$ Lower case letters represent the intron nucleotides
LINKAGE ANALYSIS BY RESTRICTION ENZYME DIGESTION OF PCR PRODUCTS

Restriction analysis was performed to confirm the polymorphisms and to provide a rapid screening for allele frequencies and linkage analysis in GSD-III families. Genomic DNA containing each of the suspected polymorphisms was amplified by PCR using a different set of primers. These primers are also listed in table 1. The amplified fragments were digested with their specific restriction enzymes: (1) fragments amplified from exon 3 (using primers 7 and 8) digested with $\mathrm{XbaI}$ for $-10 \mathrm{G} / \mathrm{A}$; (2) fragments amplified from intron 16 (using primers 9 and 10) digested with $N d e I$ for $2001+8 \mathrm{C} / \mathrm{T}$; and (3) fragments amplified from exon 25 (using primers 11 and 12) digested with $R s a \mathrm{I}$ for 3199C/T (P1067S). The digested samples were then electrophoresed on a $2 \%$ agarose gel. All the restriction enzymes used were purchased from New England Biolabs, Inc (Beverly, MA). by addition of $0.25 \mu \mathrm{l} \alpha^{32} \mathrm{P}$ dCTP $(3000 \mathrm{Ci}$ merase chain reaction (PCR) mixture. The following PCR conditions were used: an initial denaturation at $95^{\circ} \mathrm{C}$ for five minutes, then 35 cycles of denaturation at $94^{\circ} \mathrm{C}$ for one minute, annealing at $55^{\circ} \mathrm{C}$ for 30 seconds for primers 1 and $2\left(53^{\circ} \mathrm{C}\right.$ for primers 3 and 4 , and $52^{\circ} \mathrm{C}$ for primers 5 and 6 ), and extension at $72^{\circ} \mathrm{C}$ for 30 seconds, and followed by final extension at $72^{\circ} \mathrm{C}$ for 10 minutes. The PCR reactions were carried out with $1.5 \mathrm{mmol} / 1 \mathrm{MgCl}_{2}$, $400 \mathrm{nmol} / \mathrm{l}$ of each primer, and about $150 \mathrm{ng}$ genomic DNA as template. One microlitre of each PCR amplified sample was added to $10 \mu \mathrm{l}$ of stop solution ( $95 \%$ formamide, $10 \mathrm{mmol} / 1$ $\mathrm{NaOH}, 0.25 \%$ bromophenol blue, and $0.25 \%$ Xylene cyanol), denatured for five minutes in a boiling water bath, and placed immediately on ice. Then $2.5 \mu$ of each sample were loaded onto either one or both types of gels: (1) $0.75 \times$ MDE gel (AT Biochemicals, Malvern, PA) containing $5 \% \quad(\mathrm{~V} / \mathrm{V})$ glycerol; (2) $0.75 \times \mathrm{MDE}$ gel without glycerol. The gels were electrophoresed at 6-8 W either at room temperature for 18 hours or at $4^{\circ} \mathrm{C}$ for 36 hours. The gels were dried on $3 \mathrm{MM}$ Whatman paper and exposed to Kodak Biomax MR film at $-80^{\circ} \mathrm{C}$.

\section{DNA SEQUENCING}

With the SSCP analysis, sequence polymorphisms were localised to specific regions within 150 to $360 \mathrm{bp}$. To identify the exact nucleotide changes, direct sequencing of PCR amplified genomic DNA fragments without subcloning was performed with the AmpliCycle ${ }^{\mathrm{TM}}$ Sequencing kit (Perkin Elmer, Foster City, CA) using $\gamma^{32} \mathrm{P}$ dATP $(3000 \mathrm{Ci}$ $\mathrm{mmol}^{-1}, 10 \mathrm{mCi} \mathrm{ml}^{-1}$ ). In some cases the same PCR amplified genomic DNA fragments were also subcloned into $\mathrm{pCR}{ }^{\mathrm{TM}} \mathrm{TM}$ II vector with the TA cloning kit (InVitrogen, San Diego, CA). Plasmid DNA was isolated, alkaline denatured, mixed with one original PCR primer, annealed, and sequenced with Sequenase 2.0 (US Biochemicals, Cleveland, $\mathrm{OH}$ ) using $\left[{ }^{35} \mathrm{~S}\right]$ dATP. Either one or both strands were sequenced with the same sequencing primers as used in SSCP.

\section{Results}

SCREENING POLYMORPHIC MARKERS WITH SSCP Thirty-five pairs of PCR primers were designed so that they amplified the $5^{\prime}$ non-translated region as well as coding regions of each of the 35 exons, and all intron-exon junctions, of the GDE gene. SSCP analysis on MDE gels followed to detect mobility shift. The exact changes were then identified by DNA sequencing and confirmed by restriction analysis of PCR amplified genomic products using a different set of primers. The following three polymorphisms were detected.

\section{Polymorphic marker 1}

Fig 1A shows the SSCP pattern of a two allele polymorphism (allele 1: lanes 1, 2, 3, 4, 6, and 10 ; allele 2 : lanes $5,9,11,12$, and 13 ; alleles 1 and 2: lanes 7 and 8) in exon 3 of 13 unrelated controls. DNA sequencing of the subclones showed that the polymorphism was the result of a $G$ to $A$ change in the $5^{\prime}$ non-translated polymorphism was also observed in the GSDIII patients. The polymorphism created an $X b a I$ restriction enzyme site. The allele frequencies of this polymorphism were: (1) normal controls: allele 1 (corresponding to $G$ ), $50 \%$, allele 2 (corresponding to A), $50 \%$, with a heterozygosity value of 0.50 ; (2) GSD-III patients: allele $1,0.46 \%$, allele $2,0.54 \%$, with a heterozygosity value of 0.50 .

\section{Polymorphic marker 2}

Fig 2A shows a second SSCP pattern of a two allele polymorphism (allele A: lanes 1, 2, 4 , and 7; allele B: lanes 5, 8, and 10; alleles A and $B$ : lanes $3,6,9$, and 11 ) in intron 16 of the unrelated controls. DNA sequencing (fig 2B) showed that this second polymorphism was the result of a $\mathrm{C}$ to $\mathrm{T}$ change $(2001+8 \mathrm{C} /$ $\mathrm{T})$. The same polymorphism was also observed in the GSD-III patients. The polymorphism created a NdeI restriction enzyme site. The region of exon $3(-10 \mathrm{G} / \mathrm{A})$ (fig $1 \mathrm{~B})$. The same 


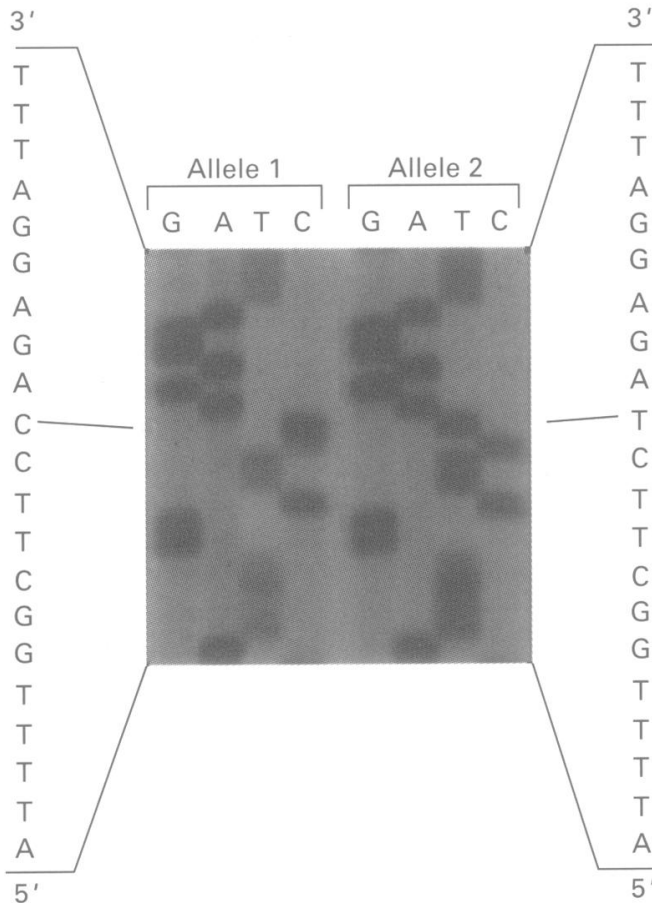

Figure 1 SSCP analysis and identification of the polymorphic marker $(-10 G / A)$ in exon 3. (A) SSCP analysis of PCR amplified genomic DNA of the unrelated controls. Allele 1: lanes 1, 2, 3, 4, 6, and 10; allele 2: lanes 5, 9, 11, 12, and 13; alleles 1 and 2: lanes 7 and 8. The gel contained $0.75 \times M D E$ with $5 \%$ glycerol and was run at $4^{\circ} \mathrm{C}$ for 36 hours. (B) Partial DNA sequences of the GDE gene subclones of two unrelated controls with different SSCP patterns. The sequences shown represented an antisense strand. The polymorphism ( $-10 G / A)$ resulting from $G$ to $A$ change is indicated.
A

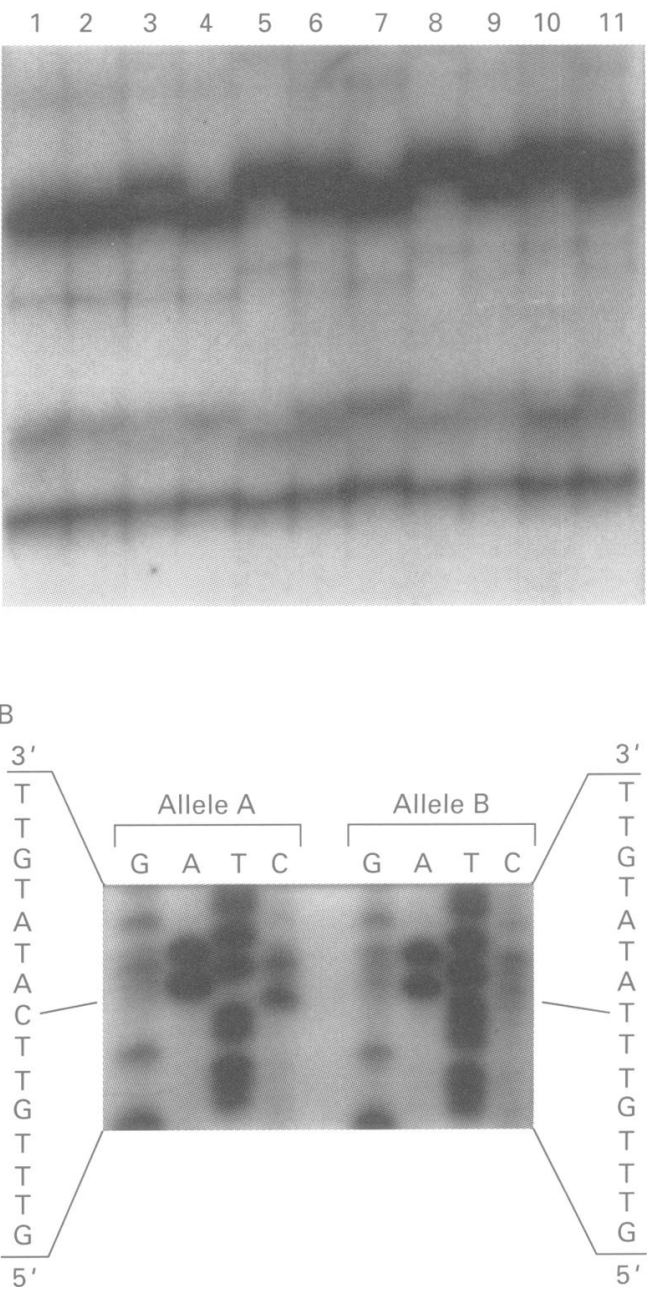

Figure 2 SSCP analysis and identification of the polymorphic marker $(2001+8 C / T)$ in intron 16 . (A) SSCP analysis of PCR amplified genomic DNA of the unrelated controls. Allele A: lanes 1, 2, 4, and 7; allele B. lanes 5,8 , and 10; alleles $A$ and $B$ : lanes $3,6,9$, and 11. (B) Partial DNA sequences of direct sequencing of PCR amplified genomic products of two unrelated controls with different SSCP patterns. The polymorphism $(2001+8 C / T)$ resulting from a $C$ to $T$ change is indicated.

allele frequencies of this polymorphism were: (1) normal controls: allele A, $64 \%$, allele $\mathrm{B}$, $36 \%$, with a heterozygosity value of 0.46 ; (2) GSD-III patients: allele A, $54 \%$, allele B, $46 \%$, with a heterozygosity value of 0.50 .

Polymorphic marker 3

There was a third SSCP pattern of a two allele polymorphism (data not shown) in the coding region of exon 25 in the unrelated controls. DNA sequencing (fig 3 ) showed that this polymorphism was the result of a $\mathrm{C}$ to $\mathrm{T}$ change at nucleotide 3199 , which changed amino acid codon proline to serine. This same polymorphism was also observed in the GSD-III patients. The polymorphism abolished an RsaI restriction enzyme site. The allele frequencies of this polymorphism were: (1) normal controls: allele I $15 \%$, allele II $85 \%$, with a heterozygosity value of 0.26 ; (2) GSD-III patients: allele I $18 \%$, allele II $82 \%$, with a heterozygosity value of 0.30 . 


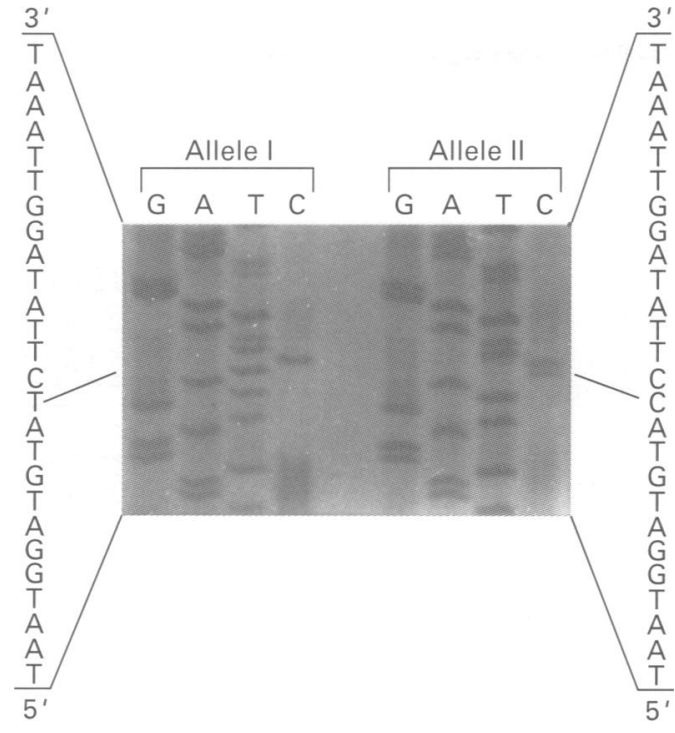

Figure 3 Identification of the polymorphic marker (3199C/T) in exon 25. Partial DNA sequences of direct sequencing of $P C R$ amplified genomic products of two unrelated controls with two different SSCP patterns. The polymorphism $(3199 C / T)$ resulting from a $C$ to $T$ change is indicated.

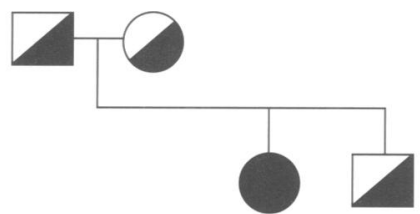

A

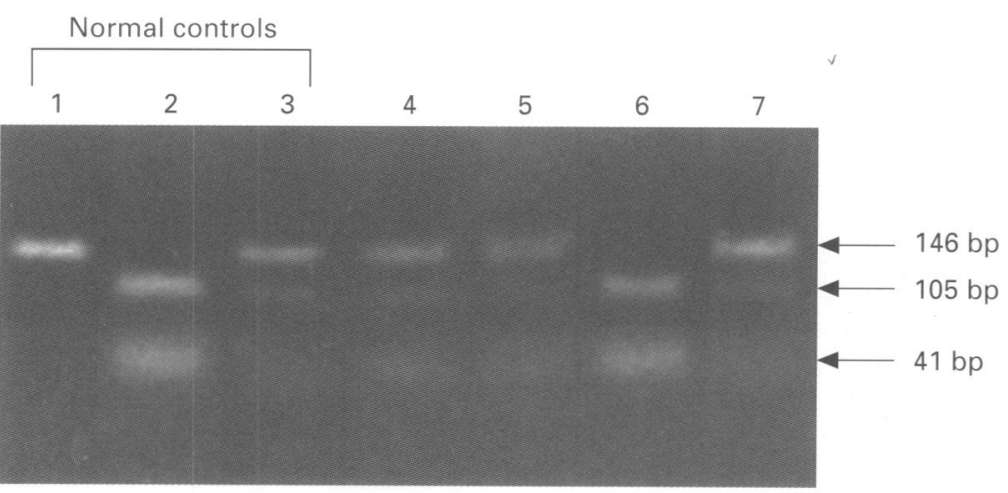

B

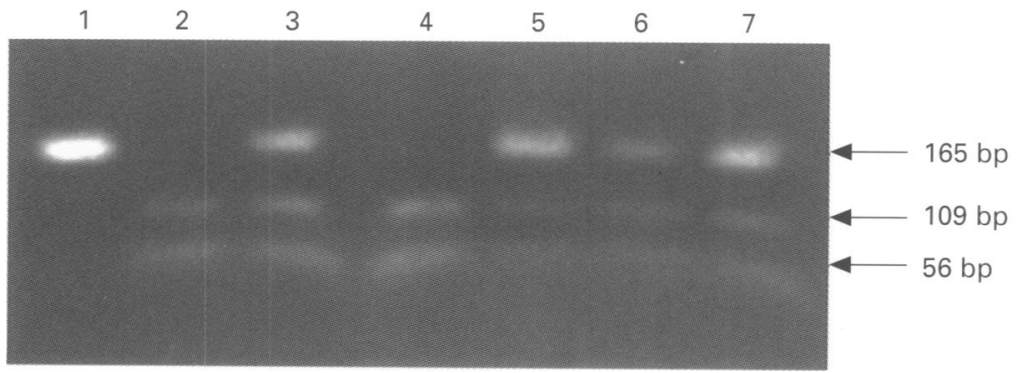

Figure 4 Linkage analysis of family 1 using the polymorphic markers (-10G/A; $2001+8 C / T$ ) by restriction digestion. (A) XbaI digestion of PCR amplified genomic DNA fragments of family 1 in exon 3. Digestion of the DNA of three unrelated controls yielded three patterns. Lane 1: completely undigested as allele 1; lane 2: completely digested as allele 2; lane 3: partially digested as alleles 1 and 2. Lanes 4, 5, and 7: father, mother, and the newborn baby, respectively, partially digested; lane 6, the affected child, completely digested. (B) NdeI digestion of PCR amplified genomic DNA fragments of family 1 in intron 16. Lane 1: completely undigested as allele A; lane 2: completely digested as allele B; lane 3: partially digested as alleles $A$ and $B$. Lane 4: father, completely digested; lanes 5 and 6: mother, the affected child, and the newborn baby, respectively, partially digested.
LINKAGE ANALYSIS BY RESTRICTION ENZYME DIGESTION OF PCR PRODUCTS

Family 1

The proband was a 14 year old female with GSD-III diagnosed by liver biopsy. The parents asked about the possibility of diagnosing GSDIII without liver biopsy in their newborn baby. Linkage analysis using cord blood DNA of the newborn was performed. Restriction analysis of polymorphic marker 1 showed that the proband had inherited allele 2 from both parents and both parents were heterozygotes for alleles 1 and 2 (fig $4 \mathrm{~A}$ ). The newborn had the same restriction pattern as the parents, indicating carrier status. Further study of polymorphic marker 2 indicated that the baby had inherited the mutant allele from his mother and the normal allele from his father (fig 4B). The infant now aged 6 months is healthy and well, without evidence of GSD-III.

\section{Family 2}

This family requested prenatal diagnosis of GSD-III at 10 weeks of gestation after two children were born with the disease. The family was completely informative for polymorphic marker 2 (data not shown). Prenatal diagnosis using linkage analysis was therefore possible. The pregnancy, however, ended in spontaneous abortion before the scheduled amniocentesis.

\section{Discussion}

RFLPs of the GDE gene in Jewish populations have been reported. ${ }^{15}$ All Jewish GSD-III patients of north African extraction have the same RFLP pattern suggesting the presence of a single mutation in that population. We report in this study three polymorphic markers in the GDE gene in the American population, the majority of whom were white, as well as a rapid PCR screening method for these markers. They were $-10 \mathrm{G} / \mathrm{A}$ in the $5^{\prime}$ non-translated region of exon $3,2001+8 \mathrm{C} / \mathrm{T}$ in intron 16 , and $3199 \mathrm{C} / \mathrm{T}$ (P1067S) in exon 25 with heterozygosity values of $0.50,0.46$, and 0.26 , respectively. The heterozygosity values were similar in GSD-III patients and unrelated normal controls, indicating that there was no linkage disequilibrium between these markers and the disease.

Carrier detection for GSD-III by measuring debranching enzyme activity has been proven to be technically difficult because the assay uses limit dextrin as the substrate and is an indirect method. ${ }^{12-14}$ On the other hand, prenatal diagnosis of GSD-III by a qualitative analysis for GDE enzyme activity or direct measurement of the enzyme activity or an immunoblot assay is possible. ${ }^{13}$ However, the immunoblot assay cannot be offered to a family in which the proband has cross reactive material to the GDE protein. The enzyme activity assay has low sensitivity as described earlier, and the qualitative assay for GDE activity requires a large number of viable cultured amniotic fluid cells or chorionic villi with and without glucose, which takes a relatively long time for cell culture, thus affecting its usefulness. Mutation analysis 
in the GDE gene is most useful for prenatal diagnosis and for carrier detection within affected families. However, the mutations we have reported so far only account for less than $30 \%$ of the total mutant alleles in GSD-III. ${ }^{1011}$ The polymorphic markers reported here have the advantage that they can be used for carrier detection requiring only a small number of uncultured cells for prenatal diagnosis. Three of the five GSD-III affected families studied were either completely informative or partially informative for these markers.

This work was supported by National Institutes of Health grant DK39078 (to YTC) and M01-RR30 (National Center for Research Sources, General Clinical Research Centers program) and a grant from the Muscular Dystrophy Association.

1 Gordon RB, Brown DH, Brown BI. Preparation and prop erties of the glycogen-debranching enzyme from rabbit liver. Biochim Biophys Acta 1972;289:97-107.

2 Bates EJ, Heaton GM, Taylor C, Kernohan JC, Cohen P. Debranching enzyme from rabbit skeletal muscle; evidence for the location of two active centers on a single polypeptide chain. FEBS Lett 1975;58:181-5.

3 Chen YT, Burchell A. Glycogen storage disease. In: Scriver $\mathrm{CR}$, Beaudet AL, Sly WS, Valle D, eds. The metabolic and molecular bases of inherited disease. 7th ed. New York: molecular bases of inherited

4 Van Hoof $F$, Hers HG. The subgroups of type III glycogenosis. Eur 7 Biochem 1967;2:265-70.

5 Ding JH, de Barsy T, Brown BI, Coleman RA, Chen YT. Immunoblot analyses of glycogen debranching enzyme in different subtypes of glycogen storage disease type III. $\mathcal{f}$ Pediatr 1990;116:95-100.

6 Yang BZ, Ding JH, Enghild JJ, Bao Y, Chen YT. Molecular cloning and nucleotide sequence of cDNA encoding human muscle glycogen debranching enzyme. $7 \mathrm{Biol}$ Chem 992;267:9294-9.

7 Liu W, de Castro ML, Takrama J, et al. Molecular cloning, sequencing and analysis of the cDNA for rabbit muscle glycogen debranching enzyme. Arch Biochem Biophys 1993; 306: $1-8$.

8 Yang-Feng TL, Zheng K, Yu J, Yang BZ, Chen YT, Kao FT. Assignment of the human glycogen debrancher gene to chromosome 1p21. Genomics 1992;13:931-4.

9 Bao Y, Yang BZ, Chen YT. Structural organization of the multifunctional human glycogen debrancher gene. $\mathrm{Am} \mathrm{f}$ Hum Genet 1993;53:662A.

10 Shen single base insertion in the $3^{\prime}$-coding region of glycogen debranching enzyme gene associated with a severe phenotype in a patient with GSD type IIIa. Hum Mutat (in press).

11 Shen J, Bao Y, Liu HM, Lee P, Leonard JV, Chen YT. Mutations in exon 3 of the glycogen debranching enzyme gene are associated with glycogen storage disease type III that is differentially expressed in liver and muscle. $\mathcal{F}$ Clin Invest 1996;98:352-7.

12 van Diggelen OP, Janse HC, Smit GPA. Debranching enzyme in fibroblasts, amniotic fluid cells and chorionic villi: pre- and postnatal diagnosis of glycogenosis type III. Clin Chim Acta 1985;149:129-34.

13 Yang BZ, Ding JH, Brown BI, Chen YT. Definitive prenatal diagnosis for type III glycogen storage disease. Am $7 \mathrm{Hum}$ Genet 1990;47:735-9.

14 Maire I, Mandon G, Mathieu M. First trimester prenatal diagnosis of glycogen storage disease type III. $\mathcal{f}$ Inherited Metabol Dis 1989;12(suppl 2):292-4.

15 Mishori-Dery A, Bashan N, Moses S, et al. RFLPs for linkage analysis in families with glycogen storage disease type III. F Inherited Metabol Dis 1995;18:207-10. 